\title{
Examining Spontaneous Assessments Mediated through Peer-to- Peer Interaction in an ESL Classroom: A Learning-Oriented Assessment (LOA) Approach
}

\author{
Kimberly Tan \\ Teachers College, Columbia University
}

\section{INTRODUCTION}

In L2 assessment research, assessments have traditionally been associated with large-scale testing or formal proficiency tests, primarily to record student achievement (Turner \& Purpura, 2016). Classroom-based assessments (CBAs), then, are seen as offshoots of large-scale tests, thus, designed similarly (Turner, 2012). However, CBAs serve a different purpose than largescale tests - CBAs primarily aim to support the teaching and learning process. As such, to address the need for a different approach in the design and development of CBAs, Turner and Purpura (2016) proposed the Learning-Oriented Assessment (LOA) framework.

LOA is "a framework for conceptualizing \& understanding how assessment data, purposefully elicited or naturally occurring in instructional or naturalistic contexts, contribute to and are moderated by instruction, learning, and other moderators of performance" (Purpura, 2020b, p. 15). It consists of seven interrelated dimensions: contextual, elicitation, proficiency, instructional, socio-cognitive, affective, and socio-interactional (Purpura, 2020a; Turner \& Purpura, 2016). Each of these dimensions can be specified individually but interact as a whole and can be used to better understand how CBAs might contribute to L2 learning.

CBAs can be planned (i.e., purposefully elicited) or unplanned (i.e., naturally occurring or spontaneous; Purpura 2020b). In this regard, assessments can be embedded into instruction or mediated through classroom interaction (Purpura, 2020b). In classroom discourse research, it has been argued that spontaneous interactions where learners have control over the discourse make a classroom more acquisition-rich (Ellis, 1998, as cited in Waring, 2011). Thus, to encourage learners' agency and promote learning, teachers seek to balance formal classroom talk and casual conversation (Waring, 2014). Yet despite the intentional inclusion of spontaneous interactions in teaching, the assessment aspect (i.e., spontaneous assessments) has been largely overlooked.

Many empirical studies related to CBAs focused on interactive assessments in general (e.g., Leung \& Mohan, 2004; Hamp-Lyons \& Tavares, 2011), or dynamic assessments (e.g., Lantolf \& Poehner, 2011; Poehner \& Compernolle, 2011) and peer-assessments (e.g., Aryadoust, 2015; Cheng \& Warren, 2005) in particular. Few studies have focused on spontaneous assessments embedded in teacher instruction mediated through interaction using the LOA approach (e.g., Purpura et al., 2016). No study, to the best of my knowledge, has used the LOA

(C) 2022 Tan. This is an open access article distributed under the terms of the Creative Commons Attribution License, which permits the user to copy, distribute, and transmit the work provided that the original authors and source are credited. 
approach to examine spontaneous assessments mediated mainly through peer-to-peer interaction. This study then aims to address the gap, contributing to the strand of CBA research that links classroom discourse with spontaneous assessments. By analyzing a stretch of interaction between a group of adult ESL students through the lens of the LOA framework (Turner \& Purpura, 2016; Purpura, 2020a), this study seeks to answer two questions: (1) What is the nature of spontaneous assessments mediated through peer-to-peer interaction? (2) To what extent is there evidence that this kind of assessment contributes to L2 processing and learning?

\section{METHOD}

The data came from 2.5 hours of video recording of an ESL class in the Community Language Program (CLP) at Teachers College, conducted via the Zoom platform. The CLP serves as a lab school, offering ESL classes to adult learners of diverse backgrounds. From the 2.5 hours of recording, a 5-minute assessment episode was identified. This episode was then transcribed using the conversation analytic method, following a modified Jeffersonian (2004) system (see Appendix A). After reviewing the transcript, the data were coded according to the dimensions of the LOA framework. Data analysis involved examining patterns and features according to the LOA dimensions and relating these observations to Purpura's (2016) meaningoriented L2 ability model and Bloom's (1956/2001) taxonomy of learning.

\section{ANALYSIS}

The analysis is organized around the seven LOA dimensions. Before addressing the two research questions, an overview of the contextual and socio-interactional dimensions is provided.

\section{Overview}

\section{Contextual Dimension}

The context of the study is an adult intermediate-level ESL conversation class. The threehour class met once a week for 10 weeks. This class is the $6^{\text {th }}$ class of the 10 classes. Nine students and a teacher were present. For this session, the lesson did not involve any specific target language structure. Instead, the lesson goal was to practice real-world communicative functions - giving presentations and participating in group discussions. Hence, the activity involved students giving a 10-minute presentation on a chosen topic, followed by a 5-minute open forum for asking questions or sharing opinions related to the presentation. After the activity, the teacher gave delayed feedback to the class and written feedback to each student.

The assessment episode chosen for analysis is the discussion after one of the student presenters, Ken's (names are pseudonyms) presentation entitled, "Why did Bath Tissue Disappear? An Interpretation from Game Theory."

\section{Socio-Interactional Dimension}


Extract 1 below shows Part 1 of the chosen assessment discourse. The discourse begins as Ken ends his presentation. From Extract 1, broadly speaking, three observations can be made. First, although the teacher opens the discussion (lines 04-09), most turns belong to two students, Ken and Mia, with minimal verbal input from the teacher and only a few interjections from other students (lines 19, 28). Second, most sequences in this stretch of talk involved question and answer sequence pairs (e.g., lines 08-09 \& 10; lines 10-12 \& 13-17; lines 33 \& 35-40), as expected given the nature of the activity. Finally, the question-and-answer sequences, which can also be considered feedback sequences, involve primarily student-student interaction, instead of the typical teacher-student interaction. Notably, both Ken and Mia wear two hats, playing both student and teacher. From a teaching perspective, Ken takes on the role of the teacher by answering Mia's questions and clarifying her understanding (e.g., lines 13-17; 20-23; 35-40). From an assessment perspective, however, it is Mia, by asking Ken a lexical meaning question (lines 10 \& 33), who plays the teacher's role of eliciting Ken's proficiency (both content and language knowledge). Concurrently, Mia also displays functional knowledge and the ability to participate in discussions by using turn-taking and turn-allocation strategies.

[1] Part 1

01 Ken: Well this is the end and I-I hope this interests you 02 help you understand what's going on and be better

03 off. Uh:: I stop here. Thank you for your attention.

04 T: Thank you Ken ((background group applause))

$05{ }^{\circ}$ that was $a^{\circ}$ interesting video. So comments on

06 the game theory of bath tissue.

$07 \quad$ (3.0)

$08 \mathrm{~T}: \quad(($ looks at the everyone on the screen, gestures))

09 Just comments feed[back what do you think,

10 Mia: ((leans forward)) [I-I-I needed to [ask you

$11 \mathrm{~T}$ :

12 Mia: about the meaning of monopolize?

13 Ken: $\mathrm{Oh}=$

$14 \mathrm{~T}: \quad=\{(($ nods $))-$ Mhm Ken. $\}$

15 Ken: Well (.) monopolize uhm ((chuckles)) uh it's-

18 Mia:

19 Bel:

20 Ken:

24 Mia:

25 Ken:

$26 \mathrm{~T}$ : monopolize is uh well uh-uh to uh:: $\mathrm{mhm}(1.5)$ to get [everything (.) in the marke[t.

[((gestures 'everything', nods $))$

[Ah (.) dominant.

Dominant (.) yes (.) Not only dominant but uh uh in this case uh:: in this supermarket if A buy everyth-all-all stock uh A is the only one buyer there so in this case A is a-a monopolist.

$\uparrow O h::$ I see I understand. [Okay thank you very much. [Uh yeah.

So it's an economic term or a:: a business term (.)
LOA dimensions

(E, P, SC, I, A)

Proficiency +

Socio-cognitive

Affective

Elicitation

(no response)

Elicitation

(reponse) + Elicit

Affective

Eliciation

Socio-cognitive

Instructional/Affect

Proficiency +

Socio-cognitive

Socio-cognitive

Socio-cognitive

Proficiency +

Socio-cognitive

Socio-cognitive

Instructional 
monopoly (.) so [a monopo- ]

29 ((group laughter, a couple of students nod $)$ )

30 T: $\quad$ hhh $\$$ Yeah $\$$ the board game also (.) monopoly is

53 Ken: the third party means gov't media or something (.)

$$
\text { monopo[lize- }
$$

Mhm good.

$$
\text { [Uhm what is in-ter-ven-tion? }
$$

Ah oh >intervention < (.) uh:: so uh-uh in my slide there were two players A and B but uh only A and B eh:: both of them cannot solve this problem and I-I mean uh-uh if they want to go to red circle to blue circle world normal world they need someone other than them.

Mia: ((nods)) Mhm,

Ken: This is government or:: media so-intervention in this case means uh well uh (0.2) uh:: well so government or media or someone outside-other than-other than these two players,

Mia: ((nods)) Mhm-hm,

$$
\text { Ken: do something uh uh:: to [change] the situation, }
$$

Mia:

Ken: change their decision. [Uh-huh]

\section{Research Question 1}

To answer research question 1, the analysis will focus on the other five LOA dimensions: elicitation, proficiency, socio-cognitive, instructional, and affective dimensions.

\section{Elicitation Dimension}

In lines 04 to 06 , the teacher elicits comments from the students. Being an open-ended question, this 'elicitation-as-instruction' can be treated as either a limited or extended production task. Her invitation was initially met with silence (line 07 ). In lines 08 to 09 , the teacher tries 
again, adding gestures. Finally, in line 10, Mia produces a limited-response turn by asking Ken a question. In this way, Mia's reply (lines 10,12) is both a second pair part to the teacher's question (lines 08-09) and a first pair part to Ken's answer (lines 15-17).

As mentioned earlier, most of the subsequent elicitation after the teacher's invitation was performed by Mia, as she asks Ken for the definition of specific words he used (lines 10, 12, 33), and later, following up with a clarification question (line 50). While her questions were limitedresponse-type tasks in format, Ken produced extended responses as he expounded on his answer.

\section{Proficiency Dimension}

As illustrated in Extract 1, the lines coded for the proficiency dimension primarily belong to Ken. He directly displayed his KSAs, both topical knowledge and linguistic knowledge. In Purpura's (2016) meaning-oriented model, which was built from the previous key L2 proficiency models (e.g., Bachman \& Palmer, 2010; Purpura, 2004), topical resources and contextual awareness were specified alongside language resources (grammatical and pragmatic), as were socio-cognitive and affective resources. Applying this model to Ken's answers, the language KSAs tapped into include forms (e.g, semantico-grammatical meaning of 'monopoly' \& 'intervention'), propositional content (i.e. economics disciplinary content), and pragmatic functional knowledge (responding \& reacting to questions; explaining abstract ideas). Business and economics KSAs, such as knowledge of concepts and real-life application of these concepts, were also used to explain the lexical meanings further. It was expected that Ken show good topical and language response since this is his area of study as a visiting fellow in the US.

As well, despite unmarked in the coding (due to space constraints), other students also demonstrated pragmatic knowledge. For example, functional knowledge related to participating in discussions includes self-selection (e.g., Mia in lines 10,33) and using discourse markers to react during interaction (e.g., lines 18, 19, 41, 46, 48). Interestingly, implicational knowledge was displayed via a cultural reference of monopoly as a board game (i.e., Jac in line 28). Apart from the economic definition being discussed as the main topic, the word Monopoly was used to refer to the well-known American board game. This shared cultural reference was well-received and acknowledged by the other participants through laughs and nods (in line 29).

\section{Socio-Cognitive Dimension}

Noticeably, the parts coded for proficiency (i.e., Ken's lines in Extract 1) are likewise marked for the socio-cognitive dimension, since these dimensions go hand-in-hand. For Ken's part, his explanations (e.g., lines 15-17, 20-23, 35-40) indicate that socio-cognitive resources being tapped included memory, reasoning, and background knowledge on game theory and current events, among others. Even while he was speaking, it appeared that he was 'thinking' and processing information, as indicated by the pauses between his talk (e.g., lines 16, 43), and by the self-initiated repairs he performed during his talk (e.g., lines 22, 44).

For the other students, their background knowledge about the toilet paper situation and business economics were also activated. All students needed to use cognitive and metacognitive strategies such as processing, comprehending, evaluating, to understand and learn what Ken was presenting, consolidate their understanding, and connect it with what they previously know. Although these mental processes are largely unseen so that we remain uncertain of the extent to 
which learning is taking place, in this case, there is some evidence indicating comprehension, at the very least. For example, Mia used discourse markers 'Mhm' (e.g., lines 41, 46, 48) to follow Ken's long explanation, before eventually declaring that she finally got it (e.g., lines 24, 58, 60). Jac, for his part, was able to connect 'monopoly' to his background knowledge of the popular board game (i.e., line 28). Meanwhile, the other students may have found this technical topic too difficult for them in terms of cognitive load. In fact, four students later admitted that they have never heard of 'Game Theory' prior to this presentation, which may be the reason why they chose to remain silent instead of speaking up during the discussion. They did, however, show indications of paying attention via gestures such as nodding, laughing, and taking down notes.

\section{Instructional Dimension}

Assistance in instructions is seen minimally when the teacher opened the floor for questions and comments. Seeing that Ken is able to answer Mia's questions on his own, the teacher does not provide further assistance to Ken. Instead, she follows through by nodding to show agreement (e.g., line 52). She also tries to clarify meaning (lines 26-27), but was cut off by Jac's reference to 'monopoly' as a board game (line 28). So the teacher shifts her talk to approve Jac's comment (lines 30-32). In this way, the lexical meaning of 'monopoly' is deepened, and there is learning opportunity with respect to both content and language.

In classroom discourse, a whole-class interaction usually involves the teacher serving as the student's main interlocutor (Kaellidi, 2013, as cited in Reddington, 2018), while pair- or small-group activities provide opportunity for student-student interactions, but the teacher often "provides instructions regarding who should speak and about what, while retaining the right to intervene" (Bannink, 2002, as cited in Reddington, 2018, p.133). Here, the task was designed to include teacher monitoring and guidance but with minimal intervention, without assigning who must speak, to maximize spontaneous peer-to-peer interactions that mirror naturalistic contexts.

\section{Affective Dimension}

Since this episode is from the $6^{\text {th }}$ class session, students had the chance to interact inperson during the first three sessions before the class moved online, so the students have grown quite comfortable with one another. As such, throughout the interaction, there is evidence that students were relaxed and engaged. For example, group applause arose naturally to show appreciation to the presenter (line 04). While not explicit in the transcript, the video recording shows that the students appeared interested and attentive. Jac freely jumps in with an insightful comment (line 28), leading to group laughter (line 29). The teacher nods to agree, acknowledge, or encourage students to continue speaking (lines 11, 14, 30, 34, 52). In general, the environment seemed conducive for stimulating student engagement and learning.

\section{Research Question 2}

To answer research question 2 , the proficiency and socio-cognitive dimensions will be further examined. Particularly, the performance of three students (i.e., Ken, Mia, Yan) in these two aspects will be compared. For this purpose, Part 2 of the discourse is presented in Extract 2. 
$62 \mathrm{~T}: \quad>$ Okay< more questions for uhm Ken?

64 Mia: Ah (.) can I ask about ((raises hand)) another one, initially

65 T: Yeah (.) yeah go=

66 Mia: =Um what is the meaning of irrational,

67 Ken: Ah (.) well uh irrational is the opposite of

68 rational uh uh:: not rational=

69 Mia: =rational me::ans=

70 Ken: =rational means uh well uh:: how about uh uh:: to be

72 Mia: Reasonable,

73 Ken: Reasonable >yeah yes< ((nods)) I think so.

74 Mia: [Okay thank you [very much,

75 T: $\quad[($ nods $))$

76 Yan

77 T: $\quad(($ nods $))$

$[\{(($ leans forward, raises hand $))-\mathrm{Uhm}\}$

78 Yan: here is the point that uh-uhm I'm afraid I cannot agree

Ken: >yeah<. well what I eh-eh was trying to say is that well-well with you ah I think > some of the people< they are not uh irrational they are rational (.) they consider the situation

88 Ken: I'm not-I'm not saying that everyone is irrational.

89 T: Yeah he's saying that everyone is rational.

90 Bel: $\quad\left\{((\right.$ nods $))-{ }^{\circ}$ true $\left.^{\circ}.\right\}$

91 Ken: I'm saying that it's a result of everyone's rational choices but uh-uh the result is- from the social point of view irrational-I mean uhm let me share the slide again((pulls up his slides to share))-(see Appendix B))

96 Ken: Well uhm everyone want to be here ((points to blue circle)) buy one buy one normal world but uh:: now we are here ((points to red circle $))$ in the-in the red circle but uh uh this is uh uh the result of everyone's rational choices (.) we are here because everyone is rational (.) but uh uh if $\mathrm{A}$ $103 \mathrm{Ken}$ : they can go to this world in the-in the blue circle, 
104 Yan: Mhm-hm,

$105 \mathrm{Ken}: \quad \mathrm{Uh}::$ So this is a socially rational world ((points to blue

106 circle $))$ this is a personally rational world ((points to red)),

$107 \quad(0.6)$

108 Yan: Oka[y (.) so uhm::

$109 \mathrm{Ken}: \quad[>$ so that's why-that's why we need a-a third party

110 intervention (.) in this- [to-eh] to-to these players.

111 Yan: $\quad$ [okay]

\section{Proficiency Dimension}

Focusing on the L2 lexis 'rational' from Extract 2, in terms of proficiency, the three students appeared to indicate different levels of lexical proficiency. For Mia, she was focused on learning the semantico-grammatical or literal meaning (Purpura, 2016) of the word, as she was in Extract 1. Although she explicitly expressed understanding of the meaning of the word 'rational', (i.e., receptive knowledge; line 74), there is no evidence thus far that she is able to use it in her own speech (i.e., productive knowledge). For Yan, she showed that she both understood the meaning and can use the word 'rational' in the correct manner (lines 78-84). However, Yan's understanding of the word 'rational' fell short of the appropriateness associated with the situational meaning (Purpura, 2016) of the word, as used in relation to the concept of 'Game Theory'. So Ken explained this nuance contextually (line 75 onwards), to clarify Yan's understanding. By successfully answering his classmates, Ken demonstrated a more holistic L2 ability, in terms of both semantico-grammatical and pragmatic knowledge (Purpura, 2016) of this particular lexical resource.

In terms of functional knowledge, Mia exhibited knowledge of the typical discourse moves, such as self-selection (line 64), active listening (line 69), and turn allocation. Yan, on the other hand, showed that she can deliver a dispreferred response (i.e., a disagreement) appropriately, by starting her turn with mitigation markers 'Uhm' and 'I'm afraid I cannot agree...' (line 78) and then giving a full account supporting her argument (lines 78-84). Ken likewise managed Yan's disagreement appropriately, prefacing his response with 'well' (e.g., lines 85,96$)$ and facilitating the discourse by turning to the assistance of visual aids (lines 94).

\section{Socio-Cognitive Dimension}

Similarly, content-wise, these three students appear to exhibit varying types of cognitive processing on this topic. According to Bloom's taxonomy (2001), there are different levels of processing learning. Where Mia displayed level 1 processing (i.e., repeating, defining), Yan displayed level 5 processing (i.e., critiquing, evaluating), and Ken displayed level 6 processing (i.e., creating, designing a presentation). Since Ken prepared this presentation, some may argue that he did not 'learn' anything new in this process and was only demonstrating what he already knew. While that may be the case, cognitive psychology research asserts that teaching is one of the most effective ways to enhance one's own learning (Chi \& Wylie, 2014) so it is likely that Ken is also learning while he was teaching his classmates. As such, although the students seemed to be using different mental processes, all of them appeared to be processing the material, albeit in different ways. Individual differences such as background knowledge, working 
memory, and level of interest, of course, play a role. Even so, it is also possible that learning may be occurring beyond what is documented in the data.

\section{DISCUSSION AND CONCLUSION}

The findings reveal that the LOA framework can be used to better understand how assessment data can be elicited, not only through teacher-student interactions but also through loosely structured student-student interactions, as monitored by the teacher. The data collected can then be used to make inferences, inform future teaching decisions and actions, and promote learning. At the same time, although it is difficult to measure the extent of students' learning during the assessment discourse itself, given that cognitive processes are largely invisible, the analysis revealed that spontaneous assessments mediated through peer-to-peer interaction can provide evidence that L2 students, at this level, are able to teach each another, and possibly, learn from each other. Since the participants are adults carrying a wealth of background knowledge, experientially and professionally, co-construction of meaning enriches the interactions.

Pedagogically, considering that teaching, learning, and assessment should be part of an integrated cycle, teachers can consider how to integrate spontaneous assessments when they purposefully design or naturally encounter spontaneous interactions in the classroom. What teachers say or do, and how much they intervene during these interactions, may also moderate students' performance. As Hall and Smotrova (2013) pointed out, teachers "can turn a classroom into either a jointly accomplished enterprise or a lonely pursuit of separate individuals physically sharing a single space." (p. 90). Having a systematic approach, then, to designing and developing interactive types of CBAs may be helpful. The LOA framework can serve as a starting point.

Some key limitations of the study involve the class size studied and the L2 proficiency level of the sample. Questions remain on how teachers in bigger class sizes can effectively conduct spontaneous assessments. For L2 classes, the student's L2 proficiency level may also play a role. Lower-level learners may not be able to produce enough meaningful output to be able to learn linguistically from each other. Future research, then, could investigate how these types of embedded CBAs can be performed in bigger class sizes, and for different L2 proficiency levels, to see if there are differences depending on these factors. Similarly, the traditional concerns of validity and reliability for CBAs remain an open question.

Still and all, as was demonstrated, spontaneous assessments mediated through peer-topeer interaction could possibly contribute to the enhancement of L2 processing and learning. As such, depending on the purpose of the assessment, intentionally incorporating these types of assessments in the classroom may be ultimately beneficial to learners. In the long run, that is what matters most.

\section{REFERENCES}

Aryadoust, V. (2015). Self- and peer-assessments of the oral presentations of first-year science students. Educational Assessment, 20(3), 199-225. 
Bachman, L., \& Palmer, A. (2010). Language assessment in practice. Oxford University Press. Bannink, A. (2002). Negotiating the paradoxes of spontaneous talk in advanced L2 classes. In C. J. Kramsch (Ed.), Language Acquisition and Language Socialization: Ecological Perspectives, (pp. 266-289). Continuum.

Bloom, B. S. (1956/2001). Taxonomy of Educational Objectives, Handbook I: The Cognitive Domain. David McKay Co Inc.

Cheng, W., \& Warren, M. (2005). Peer assessment of language proficiency. Language Testing, 22(1), 93-121.

Chi, M., \& Wylie, R. (2014). The ICAP Framework: Linking cognitive engagement to active learning outcomes. Educational Psychologist, 49(4), 219-243.

Ellis, R. (1998). Discourse control and the acquisition-rich classroom. In W. Renandya and G. Jacobs (Ed.), Learners and language learning (pp. 145-71). RELC.

Hall, J. K., \& T. Smotrova. (2013). Teacher self-talk: Interactional resource for managing instruction and eliciting empathy. Journal of Pragmatics, 47, 75-92.

Hamp-Lyons, L., \& Tavares, N. (2011). Interactive assessment - A dialogic and collaborative approach to assessing learners' oral language. In. D. Tsagari \& I. Csépes (Eds.), Classroombased language assessment (pp. 29-46). Peter Lang.

Jefferson, G. (2004). Glossary of Transcript Symbols with an Introduction. In G. Lerner (ed.) Conversation Analysis: Studies from the First Generation (pp. 13-31). John Benjamins.

Kapellidi, C. (2013). The Organization of Talk in School Interaction. Discourse Processes, 15(2), 185-204.

Lantolf, J. P., \& Poehner, M. E. (2011). Dynamic Assessment in the classroom: Vygotskian praxis for second language development. Language Teaching Research, 15(1), 11-33.

Leung, C., \& Mohan, B. (2004). Teacher formative assessment and talk in classroom contexts: Assessment as discourse and assessment of discourse. Language Testing, 21(3), 335-359.

Poehner, M. E. \& van Compernolle, R. A.(2011). Frames of interaction in Dynamic Assessment: Developmental diagnoses of second language learning'. Assessment in Education: Principles, Policy \& Practice, 18(2),183-198. http://dx.doi.org/10.1080/0969594X.2011.567116

Purpura, J. E. (2004). Assessing grammar. Cambridge, UK: Cambridge University Press.

Purpura, J. E. (2016). Assessing meaning. In E. Shohamy \& L. Or (Eds.), Encyclopedia of Language and Education, Vol. 7. Language Testing and Assessment. Springer International Publishing.

Purpura, J. E. (2020a). Lecture 2: The Learning-Oriented Assessment Framework [Lecture notes]. https://tc.instructure.com/courses/13620/pages/week-2-overview

Purpura, J. E. (2020b). Lecture 12: Examining L2 learning and learning outcomes as a result of embedded classroom assessments [Lecture notes].

https://tc.instructure.com/courses/13620/pages/week-12-overview-

2?module_item_id=270138

Purpura, J. E., Banerjee, H. L., Beltran, J., Stabler-Havener, M. (2016). Examining L2 learning and learning outcomes as a result of embedded classroom assessments. Paper presented at LTRC 2016. Palermo, Sicily.

Reddington, E. (2018). Managing participation in the adult ESL classroom: Engagement and exit practices. Classroom Discourse, 9(2), 132-149.

Turner, C. E. (2012). Classroom-based assessment. In G. Fulcher \& F. Davidson (Eds.), Routledge handbook of language testing (pp. 65-78). Routledge. 
Turner, C. E., \& Purpura, J. E. (2016). Learning-oriented assessment in second and foreign language classrooms. In D. Tsagari \& J. Banerjee (Eds.), Handbook of Second Language Assessment (pp. 255-272). De Gruyter, Inc.

Waring, H. Z. (2011). Learner initiatives and learning opportunities in the language classroom. Classroom Discourse, 2(2), 201-218.

Waring, H. Z. (2014). Managing control and connection in the language classroom. Research in the Teaching of English, 49(1), 52-74.

Kimberly Tan is a doctoral student in Applied Linguistics at Teachers College, Columbia University. Her research focuses on second language assessment. Correspondence should be sent to E-mail: ktt2122@tc.columbia.edu 